\title{
Ortaöğretim Öğrencilerinin Beden Eğitimi ve Spor Dersine Yönelik Tutumları ve Yaşam Doyumu Düzeyleri Arasındaki İlişkinin İncelenmesi: Kırıkkale İli Örneği
}

DOI: $10.26466 /$ opus.687393

*

\author{
Gonca Atik* - Aziz Güçüööver ** \\ * Y.L, Kırıkkale Üniversitesi, Sağlık Bilimleri Enstitüsü, Kırıkkale/ Türkiye \\ E-Posta: gonca.atik71@gmail.com \\ ORCID: 0000-0001-8675-1216 \\ ** Dr. Öğr. Üyesi, Kırıkkale Üniversitesi, Spor Bilimleri Fakültesi, Kırıkkale /Türkiye \\ E-Posta: azizgucluover@hotmail.com \\ ORCID: 0000-0003-1014-5011
}

\section{Öz}

Yapılan bu araştırmada, lise öğrencilerinin beden eğitimi ve spor dersine yönelik tutumları ile yaşam doyumu düzeylerinin bazı değişkenlere göre incelenmesi amaçlanmıştır. Araştırmaya 2018-2019 eğitim ve öğretim yıl içerisinde Kırıkkale ilinde bulunan liselerde öğrenim gören 874 kız ve 806 erkek olmak üzere toplam 1680 öğrenci katılmıştır. Araştırmaya katılan öğrencilerin yaşam doyumlarının belirlenmesinde "Yaşam Doyumu Ölçeği", beden eğitimi ve spor dersine yönelik tutumlarının belirlenmesinde ise "Beden Eğitimi ve Spor Tutum Ölçeği" kullanılmıştır. Elde edilen verilerin istatistiksel analiz sürecinde SPSS 22.0 programinda Independent $t$-test ve One Way Anova analizleri kullanılmıştır. Araştırmada spor bilimleri alanında yaygın olarak kullanılan betimsel araştırma yöntemlerinden tarama modeli kullanılmıştır. Bağıml değişkenler arasındaki korelasyon analizi sonuçlarına göre öğrencilerin beden eğitimi ve spor dersine yönelik tutumları ile yaşam doyum düzeyleri arasında pozitif yönde anlaml bir ilişki olduğu sonucuna ulaşılmıştır $(p<0.05)$. Sonuç olarak, lise öğrencilerinde demografik değişkenlerin beden eğitimi ve spor dersine yönelik tutum ile yaşam doyumu üzerinde önemli birer belirleyici değişken olduğu, beden eğitimi ve spor dersine yönelik olumlu tutumların yaşam doyumunu arttırdiğı görülmüştür.

Anahtar Kelimeler: Lise öğrencileri, beden eğitimi ve spor, tutum, yaşam doyumu 


\title{
Investigation of The Relationship Between the High School Students'attitudes Towards Pyhsical Education and Sports Lesson and Their Life Satisfaction Level: Kirıkkale Province Sample
}

\begin{abstract}
In this study constructed, it wasaimed to investigate the attitudes of highschool students towards physical education and sportlesson and life satisfaction levels, according to somevariables. A total of 1680 students, 874 girls and 806 boys, in highschools in Kirlkkale participated in the study in the 20182019 academicyear. "Life Satisfaction Scale" wasused to determine the life satisfaction of the studentswhoparticipated in the study, and "Physical Education and Sports Attitude Scale" wasused to determinetheirattitudestowards physical education and sportslesson. Independent t-test and One Way Anova analysiswereused in SPSS 22.0 program duringstatisticalanalysisprocess of the obtaineddata. It is for the screening model, which is one of the descriptive research methods widely used in the field of sports sciences in the research. According to the results of the correlationanalysisbetween the dependentvariables, it wasconcluded that therewas a positiverelationshipbetweenstudents' attitudestowards physical education and sportslesson and life satisfaction levels $(p<0.05)$. As a conclusion, it wasseen that demographicvariableswere important determinants of life satisfaction and attitudetowards physical education and sportslesson in highschoolstudents and positiveattitudestowards physical education and sportscourseincreased life satisfaction.
\end{abstract}

Keywords: High school students, physical education and sports, attitude, life satisfaction 


\section{Giriş}

Eğitim kavram olarak ele alındığında "birey ve toplumu bir amaca uygun ve düzgün bir hayat biçimine eriştirme konusunda mevcut değer, bilgi ve yetenekleri sistemli bir şekilde diğer nesillere ulaştırırken, aynı zamanda kişinin tutumlarını deneyimler yoluyla değiştirme süreci" şeklinde ifade edilmektedir (Harmandar, 2004, s.3). Eğitim spor faaliyetlerinin amaçlarından biridir. Bireylerin, gündelik hayatlarında uzak kalamayacakları, çeşitli amaçlar doğrultusunda eğilim gösterdikleri faaliyetlerin başında, toplumsal hayatın bir unsuru olan spor yer almaktadır. Kavram olarak değerlendirildiğinde beden eğitimi "oyun ve spor gibi fiziksel aktivitelerden oluşan, bireylerin bedensel faaliyetler içerisinde, bir başka deyişle fiziksel aktiviteler aracılığ 1 ile gelişimini hedefleyen eğitim etkinliği" olarak ifade edilmektedir (Açak, 2006, s.1). Kavram olarak spor ise "ruhsal, zihinsel ve bedensel bir olgu olan, bir takım kurallar bağlamında yapılan, mücadele azmi gerektiren, eğlenerek zaman geçirmek, sağlıklı bir hayat elde etmek, mücadele etmek ve yarışmak adına yapılan bilinçli etkinliklerin her biri" şeklinde açıklanmaktadır (Ramazanoğlu ve diğerleri, 2005, s.155). "Mutlu" bir hayat yaşamak, kuşkusuz hemen her birey için öncelikli yaşam kaygılarından biridir. Birey için mutluluk kavramının anlamı, mutlu olmanın yolları ve mutluluğun hangi unsurlardan etkilendiği gibi problemlerle "anlaşılmaya" ve "elde edilmeye" çabalanan mutluluğun, bireyler için popülerliğini yitirmeyen oldukça dikkat çekici bir konu olduğu bilinmektedir (Çivitci, 2012, s.322). Yaşam tatmini veya popüler ismiyle mutluluk, yüzyıllardır insanların dikkatini çeken konular arasında yer almıştır. Kavram olarak yaşam doyumunu açıklamak için öncelikle "doyum" sözcügüne açılık getirmek gerekmektedir. Doyum, ihtiyaçların, taleplerin, dilek ve isteklerin giderilmesidir. Yaşam doyumu kavramı ise bireyin istekleri ile mevcut olanların kıyaslanması ile varılan durum ya da sonuçtur (Özer ve Karabulut, 2003, s.72). Yaşam doyumu, genellikle bireyin bütün hayatını ve bu hayatın oldukça farklı yönlerini kapsar. Kişinin pozitif deneyimleri yaşam doyumu oranının artmasına ve olumsuz tecrübelerin ise azalmasına yol açabilir (Kabasakal ve Uz-Baş, 2013, s.28). Beden eğitimi ve spor dersi genel eğitimin hem tamamlayıcısı hem de ayrılmaz bir parçasıdır. Genel akademik bilgi düzeyinin geliştirilmesinin yanında beden eğitimi ve spor dersleri öğrencilerin kişilik gelişimlerini de destekleyen bir yapıya sahiptir. Bu yönüyle beden eğitimi ve spor dersleri öğrencilerin gelişimlerinin çok yönlü olarak 
desteklenmesinde büyük rol oynamaktadır (Türkmen ve Varol, 2017, s.755). Öğrencilerin derslere yönelik tutumları hem dersin amaçlarına ulaşmasını hem de öğrencilerin derslere yönelik ilgilerinin arttırılmasını etkilemektedir. Bu noktada beden eğitimi dersine yönelik öğrenci tutumlarını etkileyen faktörlerin incelenmesi beden eğitimi dersinin amaçlarına ulaşması için önemli bir araştırma alanı olarak karşımıza çıkmaktadır.

Literatürde özellikle yurt dışında gençlerin yaşam doyumlarının ele alındığı birçok çalışma yapıldığı görülmektedir (Tuzgöl ve Dost, 2007, s.133). Buna karşılık Türkiye' de özellikle lise öğrencilerinin yaşam doyumlarının ele alındığı ve yaşam doyumu ile beden eğitimi dersine yönelik tutum arasındaki ilişkinin incelendiği çalışmaların sınırlı olduğu görülmektedir. Bu kapsamda yapılan bu çalışmada farklı ortaöğretim kurumlarında öğrenim gören öğrencilerin beden eğitimi ve spor dersine yönelik tutumlarının karşılaştırılması ve yaşam doyumu düzeylerinin incelenmesi amaçlanmıştır.

\section{Yöntem}

\section{Araştırmanın Evreni ve Örneklemi}

Tablo 1. Araştırma Grubunu Tanımlayıcı İstatistiki Bilgiler

\begin{tabular}{|c|c|c|c|}
\hline Değişkenler & & $\mathbf{F}$ & $\%$ \\
\hline \multirow[t]{2}{*}{ Cinsiyet } & $\mathrm{Kuz}$ & 874 & 52,0 \\
\hline & Erkek & 806 & 48,0 \\
\hline \multirow[t]{4}{*}{ Sinıf düzeyi } & 9. Sinif & 462 & 27,5 \\
\hline & 10. Sinif & 523 & 31,1 \\
\hline & 11. Sinif & 392 & 23,3 \\
\hline & 12. Sinif & 303 & 18,0 \\
\hline \multirow[t]{4}{*}{ Anne eğitim durumu } & Okur yazar değil & 43 & 2,6 \\
\hline & İlköğretim & 978 & 58,2 \\
\hline & Lise ve dengi & 437 & 26,0 \\
\hline & Lisans & 222 & 13,2 \\
\hline \multirow[t]{4}{*}{ Baba eğitim durumu } & Okur yazar değil & 12 & 0,7 \\
\hline & İlköğretim & 592 & 35,2 \\
\hline & Lise ve dengi & 634 & 37,7 \\
\hline & Lisans & 442 & 26,3 \\
\hline \multirow[t]{2}{*}{ Ailede düzenli spor yapan var mı? } & Evet & 547 & 32,6 \\
\hline & Hayır & 1133 & 67,4 \\
\hline
\end{tabular}


Yapılan bu çalışmanın evreni Kırıkkale ilinde bulunan liselerde öğrenim gören 19.144 öğrenciden oluşmaktadır. Araştırmanın örneklem grubunu Kırıkkale ilinde bulunan; Fen Lisesi, Anadolu Lisesi, Kız Meslek Lisesi, Mesleki ve Teknik Lise, Imam Hatip Kız Lisesi ve Imam Hatip Erkek Lisesi'nde öğrenim gören 874 kız ve 806 erkek olmak üzere toplam 1680 öğrenci temsil etmektedir. Araştırmanın örneklem grubunu oluşturan öğrenciler evren içerisinde tesadüfî yöntem ile seçilmiştir.

\section{Veri Toplama Araçları}

Araştırmanın veri toplama sürecinde üç bölümden meydana gelen anket kullanılmıştır. Veri toplama anketinin ilk bölümünde araştırmacı tarafından hazırlanan ve 12 sorudan meydana gelen kişisel bilgi formu yer almaktadır. Araştırmaya katılan öğrencilerin yaşam doyumlarının belirlenmesinde Yaşam Doyumu Ölçeği kullanılmıştır. Ölçek, Diener ve diğerleri (1985) tarafından geliştirilen "Yasam Doyumu Ölçeği" (Dağlı ve Baysal 2016) tarafından Türkçeye uyarlanmıştır. Ölçek 1 (Hiç katılmıyorum) ile 5 (Tamamen katılıyorum) arasında değişen likert tipinde, 5 maddeden oluşan, Cronbach Alpha Katsayısı .88 olarak hesaplanmış bir kendini değerlendirme ölçeğidir. Bu araştırmada ölçeğin Cronbach Alpha katsayı değeri .84 olarak saptanmıştır. Araştırmaya katılan lise öğrencilerinin beden eğitimi ve spora karşı tutumlarına belirlenmesinde Demirhan ve Altay (2001) tarafından geliştirilen Beden Eğitimi ve Spor Tutum Ölçeği (BESTÖ) kullanılmıştır. Ölçek 12'si olumlu ve 12 'si olumsuz olmak üzere 24 maddeden oluşmaktadır. Ölçek 5'li likert tipi olup, ifadeler ( 1 = Tamamen katılmıyorum, 2 = Katılmıyorum, 3 = Kararsızım, 4 = Katılıyorum, 5 = Tamamen katılıyorum) şeklindendir. Ölçeğin geliştirilme aşamasında Cronbach Alpha güvenirlik katsayıs1 .93 olarak bulunmuştur. Bu araştırmada ölçeğin Cronbach Alpha katsayı değeri .68 olarak bulunmuştur.

\section{Verilerin Analizi}

Araştırmada elde edilen verilerin istatistiksel analiz sürecinde SPSS 22.0 programından yararlanılmıştır. Kullanılan ölçeklerin normallik düzeyleri, basıklık ve çarpıklık değerlerine bakılarak değerlendirilmiştir. Verilerin $\pm 1,5$ değer aralığında dağılım gösterdiği tespit edilmiştir. Araştırmada iki ayrı kü- 
menin verilerinin analizinde Independent t-test, çoklu grup karşılaştırmalarının analizinde One Way Anova ve Anova testlerinde farklılık yaratan grupları tespit etmek için Tukey HSD Çoklu Karşılaştırma Testi kullanılmıştır.

\section{Bulgular}

Araştırmanın bu bölümünde toplanan verilerin çözümlenmesi sonucu ortaya çıkan bulgular yer almaktadır.

Tablo 2. Öğrencilerin Beden Eğitimi Dersine Yönelik Tutum Ölçeği ve Yaşam Doyumu Ölçeği Puanlarmın Cinsiyetlerine Göre Karşılaştırılması

\begin{tabular}{llllllll}
\hline & & N & A.O. & S.S. & t & df & P \\
\hline \multirow{2}{*}{ Beden Eğitimi Dersine Yönelik Tutum } & Erkek & 806 & 2,94 &, 48 & \multirow{2}{*}{, 884} & \multirow{2}{*}{1678} & \multirow{2}{*}{, 37} \\
& Kız & 874 & 2,92 &, 42 & & & \multirow{2}{*}{, 03} \\
\multirow{2}{*}{ Yaşam Doyumu } & Erkek & 806 & 3,45 &, 93 & \multirow{2}{*}{2,806} & \multirow{2}{*}{1678} & \multirow{2}{*}{$00^{*}$} \\
\hline
\end{tabular}

$p<0,05^{*}$

Tablo 2'de görüldügüü üzere, öğrencilerin cinsiyet değişkenine göre, beden eğitimi dersine yönelik tutumlarında gruplar arasında istatistiksel olarak anlamlı bir farklılık bulunmamaktadır ( $\mathrm{p}>0.05)$.

Yaşam doyumu düzeyi ve cinsiyet değişkeni arasında ise gruplar arasında istatistiksel olarak anlamlı bir farklılık bulunmaktadır ( $\mathrm{p}<0.05)$. Erkek öğrencilerin, kı öğrencilere göre daha yüksek düzeyde yaşam doyumu düzeyine sahip oldukları tespit edilmiştir.

Tablo 3. Öğrencilerin Beden Eğitimi Dersine Yönelik Tutum Ölçeği ve Yaşam Doyumu Ölçeği Puanlarnın Simıf Düzeyine Göre Karşılaştınlması

\begin{tabular}{|c|c|c|c|c|c|c|c|}
\hline & $\begin{array}{l}\text { Gruplar arası } \\
\text { Grup içi } \\
\text { Toplam }\end{array}$ & $\begin{array}{l}\text { Kareler } \\
\text { Toplam }\end{array}$ & df & $\begin{array}{l}\text { Kareler } \\
\text { Ortalama }\end{array}$ & $\mathbf{F}$ & $\mathbf{P}$ & Tukey \\
\hline $\begin{array}{l}\text { Beden Eğitimi } \\
\text { Dersine } \\
\text { Yönelik Tutum }\end{array}$ & $\begin{array}{l}\text { Gruplar arası } \\
\text { Grup içi } \\
\text { Toplam }\end{array}$ & $\begin{array}{l}3,590 \\
344,367 \\
347,957\end{array}$ & $\begin{array}{l}3 \\
1676 \\
1679\end{array}$ & $\begin{array}{l}1,197 \\
, 205\end{array}$ & 5,524 &, $00^{*}$ & $\begin{array}{l}11<9, \\
10,12\end{array}$ \\
\hline $\begin{array}{l}\text { Yaşam } \\
\text { Doyumu }\end{array}$ & $\begin{array}{l}\text { Gruplar arası } \\
\text { Grup içi } \\
\text { Toplam }\end{array}$ & $\begin{array}{l}41,203 \\
1576,647 \\
1617,850 \\
\end{array}$ & $\begin{array}{l}3 \\
1676 \\
1679\end{array}$ & $\begin{array}{l}12,734 \\
, 941\end{array}$ & 14,600 &, $00^{*}$ & $\begin{array}{l}9<10 \\
11,12\end{array}$ \\
\hline
\end{tabular}

$p<0,05^{*}$ 
Tablo 3'te görüldüğü üzere, sınıf düzeyi değişkenine göre, öğrencilerin beden eğitimi dersine yönelik tutum ve yaşam doyumu düzeylerinde gruplar arasında istatistiksel olarak anlamlı bir farklılık bulunmaktadır $(\mathrm{p}<0.05)$. Beden eğitimi dersine yönelik tutum açısından anlamlı farklılı̆̆ın hangi gruplar arasında olduğunu belirlemek için yapılan Tukey testi sonucunda, on birinci sınıfta öğrenim gören öğrencilerin, dokuz, on ve on ikinci sınıflarda öğrenim gören öğrencilere göre beden eğitimi dersine yönelik tutumlarının olumlu yönde daha yüksek olduğu tespit edilmiştir.

Yaşam doyumu düzeyleri sınıf değişkenine göre incelendiğinde ise dokuzuncu sınıfta öğrenim gören öğrencilerin, on, on bir ve on ikinci sınıflarda öğrenim gören öğrencilere göre yaşam doyumu düzeylerinin daha yüksek olduğu belirlenmiştir.

Tablo 4. Öğrencilerin Beden Eğitimi Dersine Yönelik Tutum Ölçeği ve Yaşam Doyumu Ölçeği Puanlarnnın Anne Eğ̈itim Düzeyine Göre Karşılaştırnlması

\begin{tabular}{|c|c|c|c|c|c|c|c|}
\hline & $\begin{array}{l}\text { Gruplar } \\
\text { arası } \\
\text { Grup içi } \\
\text { Toplam }\end{array}$ & $\begin{array}{l}\text { Kareler } \\
\text { Toplam }\end{array}$ & df & $\begin{array}{l}\text { Kareler } \\
\text { Ortalama }\end{array}$ & F & $\mathbf{P}$ & Tukey \\
\hline $\begin{array}{l}\text { Beden } \\
\text { Eğitimi } \\
\text { Dersine } \\
\text { Yönelik } \\
\text { Tutum }\end{array}$ & $\begin{array}{l}\text { Gruplar } \\
\text { arası } \\
\text { Grup içi } \\
\text { Toplam }\end{array}$ & $\begin{array}{l}, 570 \\
347,38 \\
347,95\end{array}$ & $\begin{array}{l}3 \\
1676 \\
1679\end{array}$ & $\begin{array}{l}\text { 190 } \\
\text { 207 }\end{array}$ & 917 & 43 & \\
\hline $\begin{array}{l}\text { Yaşam } \\
\text { Doyumu }\end{array}$ & $\begin{array}{l}\text { Gruplar } \\
\text { arası } \\
\text { Grup içi } \\
\text { Toplam }\end{array}$ & $\begin{array}{l}11,10 \\
1606,74 \\
1617,85\end{array}$ & $\begin{array}{l}3 \\
1676 \\
1679\end{array}$ & $\begin{array}{l}3,703 \\
, 959\end{array}$ & 3,862 &, $00^{*}$ & $\begin{array}{l}\text { Lisans } \\
<\text { diğer eğitim durumları }\end{array}$ \\
\hline
\end{tabular}

$p<0,05^{*}$

Tablo 4'te görüldüğü üzere, anne eğitim durumu değişkenine göre, öğrencilerin beden eğitimi dersine yönelik tutumları ile gruplar arasında istatistiksel olarak anlamlı bir farklılık bulunmamaktadır ( $p>0.05)$. Yaşam doyumu düzeyi anne eğitim durumu değişkenine göre incelendiğinde, gruplar arasinda anlamlı bir farklılık olduğu tespit edilmiştir $(\mathrm{p}<0.05)$. Anne eğitim durumunu lisans olarak belirten öğrencilerin, anne eğitim durumunu okur-yazar değil, ilköğretim, lise ve dengi olarak belirten öğrencilere göre yaşam doyum düzeylerinin daha yüksek olduğu saptanmıştır. 
Tablo 5. Öğrencilerin Beden Eğitimi Dersine Yönelik Tutum Ölçeği ve Yaşam Doyumu Ölçeği Puanlarının Baba Ĕ̆itim Düzeyine Göre Karşılaştırılması

\begin{tabular}{|c|c|c|c|c|c|c|c|}
\hline & $\begin{array}{l}\text { Gruplar aras1 } \\
\text { Grup içi } \\
\text { Toplam }\end{array}$ & $\begin{array}{l}\text { Kareler } \\
\text { Toplam }\end{array}$ & df & $\begin{array}{l}\text { Kareler } \\
\text { Ortalama }\end{array}$ & $\mathbf{F}$ & $\mathbf{P}$ & Tukey \\
\hline $\begin{array}{l}\text { Beden } \\
\text { Eğitimi } \\
\text { Dersine } \\
\text { Yönelik } \\
\text { Tutum } \\
\end{array}$ & $\begin{array}{l}\text { Gruplar arası } \\
\text { Grup içi } \\
\text { Toplam }\end{array}$ & $\begin{array}{l}2,18 \\
345,77 \\
347,95\end{array}$ & $\begin{array}{l}3 \\
1676 \\
1679\end{array}$ & $\begin{array}{l}, 729 \\
, 206\end{array}$ & 3,533 & , $01^{*}$ & $\begin{array}{l}\text { Okur-yazar değil } \\
<\text { <iğer eğitim } \\
\text { durumları }\end{array}$ \\
\hline $\begin{array}{l}\text { Yaşam } \\
\text { Doyumu }\end{array}$ & $\begin{array}{l}\text { Gruplar arası } \\
\text { Grup içi } \\
\text { Toplam }\end{array}$ & $\begin{array}{l}2,25 \\
1615,59 \\
1617,85\end{array}$ & $\begin{array}{l}3 \\
1676 \\
1679\end{array}$ & $\begin{array}{l}753 \\
, 964\end{array}$ & 781 & ,50 & \\
\hline
\end{tabular}

$p<0,05^{*}$

Tablo 5'te, öğrencilerin beden eğitimi dersine yönelik tutumları baba eğitim durumu değişkenine göre incelendiğinde gruplar arasında istatistiksel olarak anlamlı bir fark olduğu tespit edilmiştir $(\mathrm{p}<0.05)$. Beden eğitimi dersine yönelik tutum açısından anlamlı farklılığın hangi gruplar arasında olduğunu belirlemek amacıyla yapılan Tukey testi sonucuna göre, baba eğitim durumunu okur-yazar değil olarak belirten öğrencilerin, baba eğitim durumunu ilkokul, ortaokul, lise ve lisans olarak belirten öğrencilere göre beden eğitimi dersine yönelik daha yüksek olumlu tutuma sahip oldukları saptanmıştır. Yaşam doyum düzeyi baba eğitim durumu değişkenine göre incelendiğinde, gruplar arasında istatistiksel olarak anlamlı bir fark olmadı̆̆ı belirlenmiştir $(\mathrm{p}>0.05)$.

\section{Tartışma ve Sonuç}

Araştırmada öğrencilerin beden eğitimi dersine yönelik tutumlarının cinsiyet faktörüne göre herhangi bir anlamlı farklılık göstermediği bulunmuştur. Literatürde yer alan benzer çalışma bulguları da lise öğrencilerinde beden eğitimi ve spor dersine yönelik tutumların cinsiyet değişkenine göre farklilaşmadığı görüşünü desteklemektedir (Göksel ve Caz, 2016, s.1; Uluışık, 2016, s.45 ). Cimilli (2017, s.52) tarafından spor lisesi öğrencileri üzerinde yürütülen benzer bir çalışmada öğrencilerin beden eğitimi ve spor dersine yönelik tutumlarının cinsiyetlerine göre anlamlı farklılık göstermediği tespit edilmiştir. Söz konusu çalışmada spor lisesinde kız ve erkek öğrencilerin sporla iç içe bir 
yaşam tarzına sahip olmalarının bu sonucun ortaya çıkmasında etkili olabileceği belirtilmiştir. Bu çalışmaların yanısıra Yoncalık (2011) çalışmasında, erkek öğrencilerin kızlara göre beden eğitimi derslerine daha ilgili olduklarını, erkek öğrencilerin derslerdeki motivasyon düzeylerinin ve derslerden kazanımlarının kız öğrencilere göre daha yüksek seviyede gerçekleştiğini vurgulamıştır. Doğan (2011, s.37) tarafından Niğde ilinde bulunan lise öğrencileri üzerinde yapılan çalışmada da farklı liselerde öğrenim gören öğrencilerin beden eğitimi ve spor dersine yönelik tutumlarının cinsiyet değişkenine göre farklılaşmadığı belirtilmiştir. Literatürde, erkek öğrencilerin beden eğitimi ve spor dersine katılımının yüksek olduğunu belirten çalışmalarda bulunmaktadır (Lazarevic vd., 2015; Cengiz vd., 2018). Araştırmaya katılan öğrencilerin beden eğitimi ve spor dersine yönelik tutumlarının öğrenim görülen sınıf değişkenine göre anlamlı farklılık gösterdiği tespit edilmiş, elde edilen bulgulara göre 9, 10 ve 12'inci sınıf öğrencileri ile kıyaslandığı zaman 11'inci sınıf öğrencilerinin beden eğitimi dersine yönelik tutumlarının daha yüksek olduğu bulunmuştur. Dağdemir (2018, s.40) tarafindan farklı liselerde öğrenim gören öğrenciler üzerinde yürütülen benzer bir çalışmada da diğer sınıflarda öğrenim gören öğrenciler ile kıyaslandığı zaman 9'uncu sınıf öğrencilerinin beden eğitimi ve spor dersine yönelik tutumlarının daha yüksek olduğu tespit edilmiştir. Kaya-Sarıdede $(2018$, s.6) tarafından Yalova ilinde bulunan lise öğrencileri üzerinde yürütülen çalışmada da 9'uncu sınıf öğrencilerinin beden eğitimi ve spor dersine yönelik tutumlarının 11 ve 12 'inci sınıf öğrencilerden daha yüksek olduğu bulunmuştur. Ekici ve diğerleri (2011, s.837) tarafından Muğla ilinde bulunan liselerde öğrenim gören öğrenciler üzerinde yürütülen çalışmada da öğrencilerin beden eğitimi ve spor dersine yönelik tutumlarının sınıf düzeylerine göre anlamlı farklılık gösterdiği tespit edilmiştir. Araştırmaya katılan öğrencilerin beden eğitimi dersine yönelik tutumlarının anne eğitim düzeyi değişkenine göre farklılık göstermediği, buna karşılık öğrencilerin beden eğitimi dersine yönelik tutumlarının baba eğitim düzeyine göre anlamlı farklılık gösterdiği tespit edilmiştir. Elde edilen bulgulara göre baba eğitim durumunu okur-yazar değil olarak belirten öğrencilerin, baba eğitim durumunu ilkokul, ortaokul, lise ve lisans olarak belirten öğrencilere göre beden eğitimi dersine yönelik daha yüksek olumlu tutuma sahip oldukları belirlenmiştir. Araştırma bulgularımız ile paralellik gösteren ve farklı liselerde öğrenim gören öğrenciler üzerinde yürütülen benzer bir çalışmada da ebeveyn eğitim düzeyi düşük olan öğrencilerin beden eğitimi ve 
spor dersine yönelik tutumlarının yüksek olduğu tespit edilmiştir (Demirdağ, 2018, s.42). Araştırmaya katılan öğrencilerin yaşam doyum düzeylerinin yüksek olduğu tespit edilmiştir. Literatürde yer alan benzer çalışmalarda da lise öğrencilerinin yaşam doyumlarının yüksek olduğu bulgularına ulaşılmıştır. Elmas (2013, s.40) tarafından bu konuda yapılan bir çalışmada lise öğrencilerinin yaşam doyumlarının belirlenmesi ve yaşam doyumu ile ilişkili demografik değişkenlerin incelenmesi amaçlanmış, araştırmanın sonunda öğrencilerin genel yaşam doyumlarının yüksek düzeyde olduğu tespit edilmiştir. Araştırmada öğrencilerin cinsiyetlerine göre yaşam doyumlarının anlamlı farklılık gösterdiği tespit edilmiş, elde edilen bulgulara göre erkek öğrencilerin yaşam doyum düzeylerinin kız öğrencilerden daha yüksek olduğu bulunmuştur. Literatürde lise öğrencileri üzerinde yürütülen benzer çalışma sonuçları da yaşam doyumunun erkek öğrenciler lehine yüksek olduğu görüşünü desteklemektedir (Başer-Şeker, 2009, s.51; Goldbeck ve diğerleri, 2007, s.969; Moksnes ve Espnes, 2013, s.2921). Bununla birlikte bazı çalışmalarda yaşam doyumunun kız çocukları lehine yüksek olduğu bulunmuş (Çam ve Artar, 2014; Ma ve Huebner, 2008, s.182). Araştırmada öğrencilerin yaşam doyumlarının öğrenim görülen sınıf değişkenine göre anlamlı farklılık gösterdiği tespit edilmiş, elde edilen bulgulara göre 10, 11 ve 12 'inci sınıf öğrencileri ile kıyaslandığ zaman 9'uncu sınıf öğrencilerinin yaşam doyumlarının daha yükssek olduğu tespit edilmiştir. Başer-Şeker (2009, s.51) tarafından lise öğrencileri üzerinde yürütülen benzer bir çalışmada da 9 ve10'uncu sınıflarda öğrenim gören öğrencilerin yaşam doyumlarının 11 ve 12 'inci sınıf öğrencilerinden anlamlı düzeyde daha yüksek olduğu bulunmuştur. Dursun (2016: 81) tarafından lise öğrencileri üzerinde yapılan diğer bir çalışmada ise öğrenim görülen sınıf düzeyi değişkenine göre ele alındığı zaman en düşük yaşam doyumuna 12' inci sınıf öğrencilerinin sahip oldukları tespit edilmiştir. Araştırmaya katılan öğrencilerin yaşam doyumlarının baba eğitim düzeyine göre anlamlı farklılık göstermediği, buna karşllık öğrencilerin yaşam doyumlarının anne eğitim düzeyi değişkenine göre anlamlı farklılık gösterdiği tespit edilmiştir. Elde edilen bulgulara göre anne eğitim düzeyi düşük olan öğrenciler ile kıyaslandığı zaman anne eğitim düzeyi lisans olan öğrencilerin yaşam doyumlarının daha yüksek olduğu tespit edilmiştir. Anne eğitim düzeyi yüksek olan öğrencilerde yaşam doyumunun yüksek çıkmasının temelinde 
eğitim düzeyi yüksek olan annelerin çocuklarının sorunlarını daha iyi anlamaları ve çocuklarına sosyal yaşamda daha fazla destek olmalarının yattığ düşünülebilir.

Sonuç olarak; araştırmaya katılan öğrencilerin beden eğitimi dersine yönelik tutumları ile yaşam doyumu düzeyleri arasında pozitif yönde anlamlı bir ilişki bulunduğu tespit edilmiş, bu kapsamda öğrencilerin beden eğitimi dersine yönelik tutum düzeyleri yükseldikçe yaşam doyumlarının da arttığı sonucuna ulaşılmıştır. Bu alanda yapılan çalışmalarda da spor yapan bireylerde yaşam doyumunun yüksek olduğu rapor edilmiştir (Toros, 2002: 24; Toros, 2005, s.50). Elde edilen bulgulara göre lise öğrencilerinde spora katıllmin ve spora yönelik olumlu tutumların yaşam doyumu düzeylerini arttırdığı söylenebilir. Yaşam doyumu öğrencilerin okul yaşamlarını etkileyen bir unsur olduğu için ortaöğretim öğrencilerinde yaşam doyumunu arttırmak amacıyla çeşitli sportif etkinlikler düzenlenmesini teşvik ediyoruz. 


\title{
EXTENDED ABSTRACT
}

\section{Investigation of The Relationship Between the High School Students'attitudes Towards Pyhsical Education and Sports Lesson and Their Life Satisfaction Level: Kırıkkale Province Sample}

\author{
Gonca Atik - Aziz Güçlüöver \\ Kırıkkale University
}

When taken as a concept, education is expressed as follows: "the process of changing the attitudes of the person through experiences while systematically conveying the existing values, knowledge and talents to the other generations in order to bring the individual and society to a purposeful and proper lifestyle." (Harmandar, 2004, p. 3). Education is one of the aims of sports activities. When evaluated as a concept, physical education is expressed as "an educational activity that consists of physical activities such as games and sports, which aims at the development of individuals within physical activities, in other words, through physical activities". (Açak, 2006, p. 1). Life satisfaction, or happiness by its popular name, has been among the topics that have attracted people's attention for centuries. Satisfaction is the fulfillment of needs, demands, wishes and requests. The concept of life satisfaction is the situation or result obtained by comparing the wishes of the individual with the existing ones. (Özer and Karabulut, 2003, p.72). Life satisfaction generally covers the whole life of the individual and quite different aspects of this life. Positive experiences of the person may increase the life satisfaction rate and decrease the negative experiences. (Kabasakal and UzBaş, 2013, p. 28). Physical education and sports lesson are both complementary and integral parts of general education. In addition to improving the general level of academic knowledge, physical education and sports classes also have a structure that supports students' personality development. In this respect, physical education and sports lessons play a major role in supporting students' development in many ways. (Türkmen and Varol, 2017, p.755). In the literature, it is observed that many studies have been done, especially in the study of the life satisfaction of young people abroad. (Tuzgöl and Dost, 
2007, p.133). On the other hand, it is observed that studies in Turkey, especially in which the life satisfaction of high school students is discussed and the relationship between life satisfaction and attitude towards physical education lesson are limited. In this context, the aim of this study is to compare the attitudes of the students in different secondary education institutions towards physical education and sports lessons and to examine the levels of life satisfaction.

The universe of this study consists of 19,144 students studying in high schools in Kırıkkale province. A total of 1680 students, including 874 girls and 806 boys from Science High School, Anadolu High School, Girls' Vocational High School, Vocational and Technical High School, Imam Hatip (Religious) Girls' High School and Imam Hatip Boys' High School in Kirıkkale province, represent the sample group of the study. The students forming the sample group of the research were selected by random method in the universe.

A questionnaire consisting of three parts was used in the data collection process of the research, In the first part of the data collection questionnaire, there is a personal information form consisting of 12 questions prepared by the researcher. The Life Satisfaction Scale was used to determine the life satisfaction of the students who participated in the study. The "Life Satisfaction Scale" developed by Diener et al. (1985) was adapted to Turkish by Dağlı and Baysal (2016). The scale is a self-assessment scale with 5 items in Likert type ranging from 1 (I do not agree) to 5 (I totally agree) and Cronbach Alpha Coefficient is .88. In this study, the Cronbach Alpha coefficient value of the scale was found to be 0.84 . Physical Education and Sports Attitude Scale (BESTÖ) developed by Demirhan and Altay (2001) was used to determine the attitudes of high school students participating in the study towards physical education and sports. The scale consists of 24 items, 12 of which are positive and 12 of which are negative. Cronbach Alpha reliability coefficient was found to be 0.93 during the development of the scale. In this study, the Cronbach Alpha coefficient value of the scale was found to be 0.68 .

SPSS 22.0 program was used in the statistical analysis process of the data obtained in the research. The normality levels of the scales used were evaluated by looking at the kurtosis and skewness values. It was determined that the data ranged within \pm 1.5 value range. In the study, The Independent t-test for the analysis of data from two separate clusters, the One-Way ANOVA for the analysis of multiple group comparisons, and the Tukey's HSD Multiple 
Comparison Test were used to identify the disparate groups in the Anova tests.

There was no statistically significant difference between the groups in students ' attitudes towards physical education lesson according to gender variable ( $p>0.05)$. There was a statistically significant difference between the levels of life satisfaction and gender $(p<0.05)$. Male students were found to have a higher level of life satisfaction than female students. According to the grade level variable, there is a statistically significant difference between the groups in the attitudes and life satisfaction levels of the students towards physical education lesson $(\mathrm{p}<0.05)$. According to the maternal education status variable, there is no statistically significant difference between students' attitudes towards physical education lesson and groups $(p>0.05)$. When the attitudes towards physical education lesson were examined according to the educational status of the father, a statistically significant difference was found between the groups $(\mathrm{p}<0.05)$.

In the study, it was found that students' attitudes towards physical education lessons did not show any significant difference according to gender factor. Similar study findings in the literature also support the view that attitudes towards physical education and sports lessons do not differ according to gender variable in high school students. (Göksel and Caz, 2016, p.1; Uluışı, 2016, p.45). In a similar study conducted by Cimilli (2017, p.52) on sports high school students, it was found that students' attitudes towards physical education and sports lessons did not differ significantly according to their gender. It was stated in the study in question that female and male students having a lifestyle intertwined with sports in sports high school may be effective in this result. In addition to these studies, Yoncalı (2011) emphasized that male students are more interested in physical education lessons than girls, and the motivation levels and gains of male students are higher than female students. In the study conducted by Doğan (2011, p.37) on high school students, it was stated that the attitudes of students studying in different high schools to physical education and sports lessons did not differ according to gender. In the literature, there are studies stating that male students have high participation in physical education and sports lessons (Lazarevic et al., 2015; Cengiz et al., 2018). In the study conducted by Ekici et al. (2011, p.837) on students studying in high schools, it was found that students' attitudes towards physical education and sports lessons differ significantly 
according to their grade levels. It was determined that the attitudes of the students participating in the study towards physical education lessons did not differ according to the variable of educational status of the mother, whereas the attitudes of the students towards physical education lessons differed significantly according to the educational status of the father.

As a result; It has been determined that there is a positive significant relationship between the attitudes of the students participating in the research towards physical education lesson and their life satisfaction levels and in this context, it was concluded that as the attitude levels of students towards physical education lesson increased, their satisfaction with life increased. In studies conducted in this field, it has been reported that life satisfaction is high among individuals doing sports (Toros, 2002, p.24; Toros, 2005, p.50). According to the findings, participation in sports and positive attitudes towards sports can be said to increase life satisfaction levels in high school students. As life satisfaction is an element affecting the school life of students, we encourage organizing various sports activities in order to increase the life satisfaction of secondary school students.

\section{Kaynakça / References}

Açak, M. (2016). Beden Eğitimi Öğretmeninin El Kitabı, Morpa Kültür Yayınları, İstanbul.

Başer Şeker, G. (2009). Lise öğrencilerinin bağlanma stilleri ve yaşam doyumlarnnı incelenmesi. Yüksek Lisans Tezi. Gazi Üniversitesi Eğitim Bilimleri Enstitüsü.

Cengiz, Ö., Kılıç, M. A., ve Soylu, Y. (2018). Ortaokul öğrencilerinin beden eğitimi dersine yönelik tutumlarının incelenmesi. Sosyal Bilimler Akademi Dergisi, 1(2), 141-149.

Cimilli, V. (2017). Spor lisesi öğrencilerinde bedensel / kinestetik zekâ ile beden eğitimi dersine yönelik tutum düzeyleri arasındaki ilişkisinin incelenmesi: İstanbul Örneği. Yüksek Lisans Tezi. Atatürk Üniversitesi Eğitim Bilimleri Enstitüsü.

Çam, Z., Artar, M. (2014). Ergenlikte yaşam doyumu: Okul türleri bağlamında bir inceleme. Muş Alparslan Ünizversitesi" Sosyal Bilimler Dergisi, 2(1), 23-45.

Çivitci, A. (2012). Üniversite öğrencilerinde genel yaşam doyumu ve psikolojik ihtiyaçlar arasındaki ilişkiler. Ç.Ü. Sosyal Bilimler Enstitüsü Dergisi, 21(2), 321-336.

Demirdağ, R. (2018). Farklı tür liselerdeki öğrencilerin beden eğitimi ve spor dersine ilişkin tutumlarımın karşllaştırmalı olarak incelenmesi: Erzurum ili örneğgi. Yüksek Lisans Tezi. Ağrı İbrahim Çeçen Üniversitesi Sosyal Bilimler Enstitüsü. 
Doğan, N. (2011). Niğde ilinde bulunan farklı statüdeki liselerde eğitim gören öğrencilerin beden eğitimi dersine karşı tutumları ve fiziksel uygunluk düzeylerinin araştırılması. Yüksek Lisans Tezi. Niğde Üniversitesi Sosyal Bilimler Enstitüsü.

Dursun, H. (2016). Lise öğrencilerinin değer tercihleri ve yaşam doyumları arasındaki ilişki. Yüksek Lisans Tezi. Atatürk Üniversitesi Eğitim Bilimleri Enstitüsü.

Ekici, S. ve Bayrakdar, A., Hacıcaferoğlu, B. (2011). Lise öğrencilerinin beden eğitimi dersi tutumlarının değerlendirilmesi, Uluslararası İnsan Bilimleri Dergisi. 8(1),831-839.

Elmas, İ.H. (2013). Ortaöğretim öğrencilerinin hayat tatmin düzeyleri. Yüksek Lisans Tezi. Hasan Kalyoncu Üniversitesi Sosyal Bilimler Enstitüsü.

Goldbeck L., Schmitz T.G., Besier T., Herschbach P. ve Henrich G (2007). Life satisfaction decreases during adolescence. Qual Life Res, 16, 969-979.

Göksel, A.G., Caz, Ç. (2016). Anadolu lisesi öğrencilerinin beden eğitimi dersine yönelik tutumlarının incelenmesi. Marmara Üniversitesi Spor Bilimleri Dergisi, 1(1),1-9.

Harmandar, İ.H. (2004). Beden eğitimi ve sporda özel öğretim yöntemleri. Ankara:Nobel Yayın Dağıtım.

Kabasakal, Z. ve Uzbaş, A. (2013). Öğretmen adaylarında yaşam doyumunun yordayıcısı olarak problem çözme becerileri. Ĕğitim ve Öğretim Araştırmalarn Dergisi, 2(1), 27-32.

Kaya Sarıdede, Ş. (2018). Ortä̈ğretim öğrencilerinin beden eğitimi dersine ilişkin tutumlarının incelenmesi. Yüksek Lisans Tezi. İstanbul Gelişim Üniversitesi Sağlık Bilimleri Enstitüsü.

Lazarevic, D., Orlic, A., Lazarevic, B., ve Janic, S. R. (2015). Attitudes of early adolescent age students towards physical education. Physical Culture, 69(2), 88-98.

MA C.Q, ve Huebner, E.S. (2008). Attachmentrelationships and adolescents' lifesatısfaction: somerelationshipsmattermore to girlsthanboys. Psychology in the Schools, 45(2), 177-187.

Moksnes, U.K. ve Espnes, G.A. (2013). Self-esteem and life satisfaction in adolescents-gender and age as potentialmoderators. Springer Science Business, 22(10), 2921-2928.

Özer, M., ve ÖzsoyKarabulut, Ö. (2003). Yaşlılarda yaşam doyumu. Turkish Journal of Geriatrics, 6(2),72-74. 
Ramazanoğlu, F., Karahüseyinoğlu, M.F., Demirel, E.T., Ramazanoğlu, M.O. ve Altungül, O. (2005) Sporun toplumsal boyutlarının değerlendirilmesi. Doğu Anadolu Bölgesi Araştırmaları, 153-157.

Toros, T. (2002). Elit ve elit olmayan erkek basketbolcularda hedef yönelimi, güdüsel (motivasyonel) iklim ve yaşam doyumu. Hacettepe Spor Bilimleri Dergisi, 13(3), 24-36.

Toros, T. (2005). Genç basketbolcuların oyunda kalma süreleri ile hedef perspektif yaklaşımı, yaşam doyumu ve algılanan motivasyonel iklim arasındaki ilişki. Hacettepe Spor Bilimleri Dergisi, 16(2), 50-63.

Tuzgöl Dost, M. (2007). Üniversite öğrencilerinin yaşam doyumunun bazı değişkenlere göre incelenmesi. Pamukkale Üniversitesi Ĕ̆itim Fakültesi Dergisi, 2(22), 132-142.

Türkmen, M. ve Varol, R., (2017). İmam hatip ortaokullarındaki öğrencilerin beden eğitimi ve spor dersine ilişkin tutumlarının araştırılması: Bartın il örneği. Electronic Turkish Studies, 12(25), 750-762

Uluışı, V. (2016). Ortaöğretim öğrencilerinin beden eğitimi dersine yönelik tutumlarının sınıf ve cinsiyet değişkenlerine göre incelenmesi. Uluslararası Multidisipliner Akademik Araştırmalar Dergisi, 2(3), 45-53.

Yoncalık, O. (2011). The physical education lesson in Turkish primary schools, affective entry characteristics and gender. SAJRSPER, 33(2), 157-168.

Zengin, S., Hekim, M. ve Hekim, H. (2016). Ortaokul ve lise öğrencilerinin beden eğitimi dersine yönelik tutumlarının cinsiyet ve öğrenim kademesi değişkenine göre incelenmesi. Journal of Human Sciences, 13(2),3243-3248.

\section{Kaynakça Bilgisi / Citation Information}

Atik, G. ve Güçlüöver, A. (2020). Ortaöğretim öğrencilerinin beden eğitimi ve spor dersine yönelik tutumları ve yaşam doyumu düzeyleri arasındaki ilişkinin incelenmesi:Kırıkkale ili örneği. OPUSUluslararası Toplum Araştırmaları Dergisi, 15(23), 1959-1975. DOI: 10.26466/opus.687393 